\title{
Thermo-Economic Assessment of the First Integrated Solar Combined Cycle System of Hassi R'mel
}

\author{
M. AMANI*, A. SMAILI**, A. GHENAIET*** \\ *Laboratoire de Génie Mécanique et Développement, Ecole Nationale Polytechnique, P.B. 182 El-Harrach, 16200, \\ Algiers, Algeria,E-mail: madjid.amani@g.enp.edu.dz \\ **Laboratoire de Génie Mécanique et Développement, Ecole Nationale Polytechnique, P.B. 182 El-Harrach, 16200, \\ Algiers, Algeria, E-mail: arezki.smaili@g.enp.edu.dz \\ ***Laboratory of Energetic Mechanics and Conversion Systems, University of Sciences and Technology \\ Houari Boumediene, BP32 El-Alia Bab-Ezzouar 16111, Algiers, Algeria
}

cross'ref http://dx.doi.org/10.5755/j01.mech.26.3.23992

\section{Introduction}

The global energy consumption has increased rapidly leading to the global warming as a result of emissions of carbon dioxide and methane into the atmosphere [1] added to the shrink in fossil energy availability, all these made the recourse for efficient energy conversion and development of renewable energy ever more critical. The integration of solar energy via the combination of concentrated solar power technology (CSP) with combined cycle (CC) has resulted in less capital cost and continuous power supply, in addition to thermal efficiency improvement and $\mathrm{CO}_{2}$ emission reduction [2]. One of the systems that will be further discussed is that of an integrated solar combined cycle (ISCC), incorporating the technology of parabolic trough collectors (PTC). A number of CSP plants are under development over the world, typically nine large commercial-scale solar power plants of $354 \mathrm{MW}$ installed in the Mojave Desert and several others operating in Italy, Iran and North-Africa.

Various previous techno-economic studies have investigated the performance of ISCC technology. Dersch et al. [3] found that the integration of PTC technology with CC plant provides an interesting way for solar electricity generation, in addition to the environmental and economic benefits. Montes et al. [4] showed the benefit of coupling the solar field to CC, evidently in a hot dry climate such as in Las-Vegas and Almeria, where the good coupling of solar thermal power made ISCC to operate efficiently and the cost of solar electricity decreases. Antonanzas et al. [5] found that the solar hybridization with $\mathrm{CC}$ installed through Spain has increased electricity production in the peak hours corresponding to high solar radiation as well as the overall thermal efficiency and $\mathrm{CO}_{2}$ emission has reduced. Zhu et al. [6] examined the thermodynamic impact of the integration of solar energy into CC power plant operating either with two gas turbines (GT), one steam turbine and two heat recovery steam generators (HRSG) with an optional duct burner to boost the overall power.

With PTC technology the solar energy is concentrated and transferred to Heat Transfer Fluid (HTF) which is generally synthetic oil in the absorber tube and then via an intermediate oil-to-water/steam heat exchanger is transmitted into the Rankine cycle. Betaineh. [7] developed a transient thermal model to investigate the performance of the solar steam generation plant (SSGP) using PTC technology under different parameters. The optimal SSGP con- figuration shows a higher reliability in terms of steam generation for an industrial application. Benabderrahmane et al. [8] investigated the heat transfer of a non-uniformly heated parabolic trough solar collector receiver equipped by two longitudinal fins using a turbulent forced convection nanofluid. The obtained results show that with two model phase exhibit a higher convective heat transfer coefficient as well as smaller nanoparticles enhances the convective heat transfer.

A comparative study [9] between solar Rankine cycle (SRC) and ISCC plants based on PTC/solar tower system and a molten salt to transfer heat to the water loop in SRC and to the synthetic oil (Therminol VP-1) in ISCC, showed that with the same aperture area of solar field the coupling with PTC caused low performance since less quantity of solar energy is intercepted compared to heliostat field. Abdel Dayem et al. [10] simulated the Kuraymat (Egypt) ISCC using TRNSYS and compared the predicted thermodynamic performance with the measured data under the same conditions of design specifications and weather, with a good agreement. Aldali et al. [11] studied the thermodynamic performance of ISCC under Libyan weather conditions where two operation modes with the same solar field area were considered: fuel saving and power boosting.

Besides the thermodynamic study, an economic assessment is required from the point of view of viability for electricity production, where levelized cost of energy (LCOE) is suitable for such a study. Price et al. [12] quantified the cost reduction potential of LCOE for different configurations of solar energy integration. Horn et al. [13] investigated the technical and economic aspects of ISCC installation in Egypt; therefore, a comparative study between ISCC using PTC technology and solar tower technology was carried out and allowed to conclude that from the point of view of electricity cost generation and environmental effect HTF is an attractive technology. Similarly, Hosseini et al. [14] assessed the technical and economic aspects for six different sizes of ISCC power in Iran. Based on LCOE assessment when the environmental effect is considered, ISCC using $67 \mathrm{MW}$ integrated to $\mathrm{CC}$ is the best choice for the construction of the first solar power plant in Iran. Also, Mokheimer et al. [15] made a technoeconomic comparative study to integrate three types of CSP technologies (PTCs, LFR and Solar Tower) with a conventional GT cogeneration plant under Dhahran (Saudi Arabia) weather conditions, where THERMOFLEX with 
PEACE software were used for this integration with different gas turbines (GT) 50-150 MW. It is having been found that the LFR technology is the optimal configuration of solar integration with the steam side of GT cogeneration with 50 MWe output. Duan et al. [16] proposed a novel solar integration with CC (HRSG has two pressure levels) using PTC technology and a part of a compressed air from the compressor is used as HTF through the receiver of solar PTC field. This novel ISCC using compressed air has more advantage in terms of performance and economy compared to ISCC using oil as HTF. Li et al. [17] presented a novel integration of solar energy into CC with two different pressure and temperature levels in heat recovery steam generation (HRSG) using concentrating and nonconcentrating solar systems which are PTC using DSG system and evacuated tube (ET). As results, these two types of solar-collectors in a temperature cascade way contributed positively in the power plant performance in terms of solar heat conversion efficiency and lowering LCOE cost achieved compared to ISCC-DSG system power plant. Behar et al. [18] studied the performance of first ISCC plant in Algeria and showed that the power can reach about 134 MW with high efficiency. Derbal-Mokrane et al. [19] developed a mathematical model and simulating the ISCC performance in Hassi R'mel (Algeria) site using TRNSYS simulation program. Achour et al. [20] investigated in detail the thermal performance of ISCC in south of Algeria and the results obtained might serve as guidelines for the future development of such system in this country.

To our knowledge, most of the published studies about the development ISCC power plants in Algeria have been focused on the investigation of thermal performance and obtained results can provide some guidelines and suggestions for the development of such solar thermal plants among the ambitious renewable energy program of Algeria at the horizon 2030. The present study deals with thermodynamic and economic assessment of ISCC power plants integrating a Heat Solar Steam Generator (HSSG) and using the solar thermal energy collected by HTF through PTC, thus the economic assessment based on the levelized cost of energy (LCOE) method demonstrates the feasibility and competitiveness of such a system in Algerian renewable energy program that is announced in 2011 or for any other country adopting a typical ISCC power plant with respect to the environmental issue. Validation is carried out upon the first ISCC under Hassi R'mel weather conditions, which during daily light operates as ISCC, while it operates as a conventional $\mathrm{CC}$ during the night or cloudy days. HSSG operates as a boiler in parallel to HRSG for enhancing the quantity of steam generated during the sunny periods, thus only an evaporator section is used to avoid the use of preheating and superheating exchangers. The heat exchangers are the important subsystem for the present analysis, hence the method of pinch point and approach point are used in the thermodynamic modelling. Under the Saharan climate with the diurnal variation of the solar radiation, the obtained results showed the feasibility of such technology which may serve as a support and guide in further installations.

\section{Thermodynamic modelling}

As shown by Fig. 1, ISCC consists of two GT units and ST unit, two HRSG with a simple pressure level and one HSSG working in parallel with HRSG evaporators and solar field without storage or back-up system. During the cloudy periods and night, the power plant operates as a conventional $\mathrm{CC}$, while in the sunny periods one part of feed water is withdrawn from HRSG and converted into saturated steam by HSSG and then returned to HRSG where it is mixed and superheated. The supplement of solar thermal energy provides an increase in steam mass flow of the Rankine cycle. The thermal performances and economic assessment based on the LCOE method of the present system are predicted using a MATLAB code under the geographical of the Hassi R'mel region and the climate conditions corresponding to the $21^{\text {st }}$ day of March for the maximum of DNI. The design point of ISCC does not consider the solar energy. With the availability and variation of DNI during the day the generated superheated steam mass flow varies through heat exchangers network and thus leads to the off-design operation. HRSG is considered as the main subsystem where all the thermal energy is transferred to generate the superheated steam. At the design mode the selection of the pinch and approach points for the evaporator is required to predict HRSG performance while operating in off-design mode. The heat loss and the pressure drop of steam are neglected in both HRSG and HSSG.

Based on the pinch point and approach point method, the gas and steam mass flow rates and temperatures are the key parameters of the present analysis.

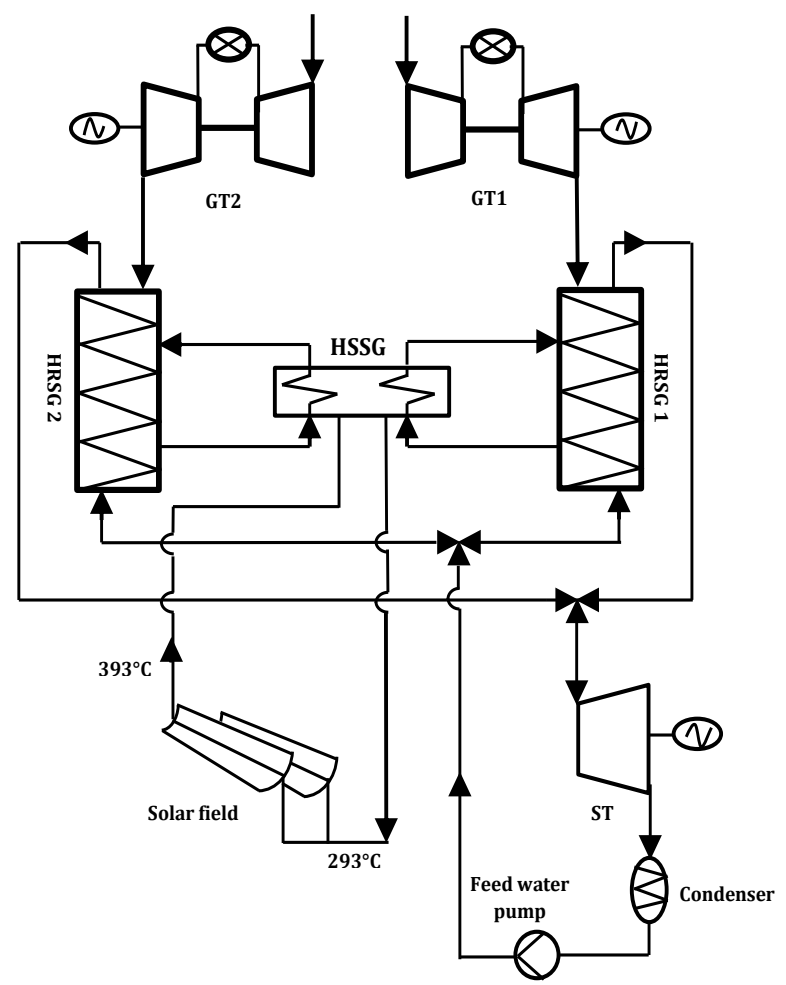

Fig. 1 Schematic of ISCC power plant

\subsection{Solar field analysis}

To evaluate the thermal performance of the solar field, the energy balance between solar radiation and heat absorption by HTF and heat losses are estimated. HTF is the synthetic oil Therminol VP-1 which presents a proven maturity in all solar thermal power plants of an operational temperature range of $13^{\circ} \mathrm{C}-395^{\circ} \mathrm{C}$ limited by the thermal stability [21]. The useful solar energy gained through the 
absorber of PTCs is obtained by an equation due to Zarza [22]:

$$
Q_{c}=A_{c} D N I \cos \theta \eta_{\text {optic }} K(\theta)-A_{a b s} U_{a b s}\left(T_{a b s}-T_{a}\right),
$$

with $D N I$ is the direct normal radiation expressed by the following equation:

$$
D N I=\tau_{b} I_{s o} \cos \theta_{z},
$$

where: $I_{\text {so }}$ is the extraterrestrial radiation and $\theta$ is the angle of incidence.

The adopted estimation of the direct solar radiation intensity is that of Hottel method [23]. The incidence angle modifier is given as follows:

$$
K(\theta)=1-2.2307310^{-4}(\theta)-1.110^{-4}(\theta)^{2}-3.18510^{-6}(\theta)^{3}-4.85510^{-8}(\theta)^{4} .
$$

The absorber temperature $T_{a b s}$ is evaluated by the Eq. (4):

$$
T_{a b s}^{4}=\left(\alpha D N I C_{c} \frac{\eta_{\text {optic }}}{\sigma \varepsilon}\right)+T_{a}^{4}
$$

The heat loss coefficient depends on the absorber temperature, determined experimentally by performing specific thermal loss tests with the solar collector operating at several temperatures within the corresponding typical working temperature range. The variation of thermal loss coefficient $U_{a b s}$, versus the receiver pipe temperature is usually expressed with a second order polynomial equation, with $a, b$ and $c$ obtained experimentally:

$$
U_{a b s}=a+b\left(T_{a b s}-T_{a}\right)+c\left(T_{a b s}-T_{a}\right)^{2} .
$$

Table 1 below gives the values of the coefficients $a, b$ and $c$ obtained experimentally.

Table 1

Coefficients $a, b$ and $c$ [22]

\begin{tabular}{|c|c|c|c|}
\hline$T_{a b s},{ }^{\circ} \mathrm{C}$ & $a$ & $b$ & $c$ \\
\hline from 200 to 300 & 1.433242 & -0.00566 & 0.000046 \\
\hline up to 300 & 2.895474 & -0.0164 & 0.000065 \\
\hline
\end{tabular}

The solar field performance is the useful solar energy, HTF mass flow and the solar field efficiency. The total useful energy $Q_{S F}$ gained by $H T F$ is given by:

$$
Q_{S F}=N_{L} C_{L} Q_{C},
$$

where: $C_{L}, N_{L}$ are respectively, the number of collectors in each row and the number of lines in the solar field.

$H T F$ mass flow $\dot{m}_{S F}$ is given by:

$$
\dot{m}_{S F}=\frac{Q_{S F}}{C_{p, H T F} \Delta T_{S F}} .
$$

The solar field efficiency $\varepsilon_{S F}$ is the ratio of the net useful energy gained by $H T F$ in the solar field and the total quantity of solar beam reaching the mirrors:

$$
\varepsilon_{S F}=\frac{Q_{S F}}{D N I A_{C} N_{L} C_{L}} .
$$

The solar field parameters and specifications are given in the Tables from 2 to 5 :
Table2

Solar collector specifications [24]

\begin{tabular}{|c|c|}
\hline Parameters & Values \\
\hline Aperture area $A_{c}, \mathrm{~m}^{2}$ & 817.5 \\
\hline Concentration ratio $C_{c}$ & 82 \\
\hline Optical efficiency $\eta_{\text {optic }}$ & 0.80 \\
\hline
\end{tabular}

Table3

Solar field operation parameters [24]

\begin{tabular}{|c|c|}
\hline Parameters & Values \\
\hline Number of collectors in each row & 4 \\
\hline Number of lines & 56 \\
\hline$H T F$ inlet temperature $T_{H T F, i},{ }^{\circ} \mathrm{C}$ & 293 \\
\hline$H T F$ outlet temperature $T_{H T F, o},{ }^{\circ} \mathrm{C}$ & 393 \\
\hline$\Delta T_{S F}=\left(T_{H T F, o}-T_{H T F, i}\right),{ }^{\circ} \mathrm{C}$ & 100 \\
\hline Solar field area, $\mathrm{m}^{2}$ & 183120 \\
\hline
\end{tabular}

Table 4

Collector optical performances [25]

\begin{tabular}{|c|c|c|c|}
\hline Parameters & Symbols & values & units \\
\hline Intercept factor & $\gamma$ & 96 & $\%$ \\
\hline Absorptivity & $\alpha$ & 95 & $\%$ \\
\hline Reflectivity & $\rho$ & 98 & $\%$ \\
\hline $\begin{array}{c}\text { Atmospheric trans- } \\
\text { missivity }\end{array}$ & $\tau_{b}$ & 97 & $\%$ \\
\hline
\end{tabular}

Table 5

Hassi R'mel data [26]

\begin{tabular}{|c|c|c|c|}
\hline \multicolumn{4}{|c|}{ Parameters } \\
\hline Latitude & $\varphi$ & 33.8 & degree \\
\hline Ambient temperature & $T_{a}$ & 20 & ${ }^{\circ} \mathrm{C}$ \\
\hline Solar constant & $I_{s c}$ & 1367 & $\mathrm{~W} / \mathrm{m}^{2}$ \\
\hline Relative humidity & $R H$ & 58 & $\%$ \\
\hline
\end{tabular}

\subsection{GT model}

The real gas flow properties and the thermodynamic processes with specific heat as function of temperature with the cooling effect [27-29]. An experimental correlation is used to estimate the mass flow rate of the cooling system. The work of the turbine $W_{T}$ is summed from $W_{g e}, W_{a e}$ which are the works of expansion gases and expansion cooling air respectively. The work of the gas turbine $W_{G T}$ is the difference between that produced by the turbine and that consumed by the compressor including the transmission loss. 


$$
W_{G T}=\left(\frac{W_{T}-W_{C}}{\eta_{m}}\right),
$$

where:

$$
W_{T}=W_{g e}+W_{a e}
$$

For a given power $P_{G T n e t}$, the required air mass flow is estimated as:

$$
\dot{m}_{a}=\frac{P_{G T n e t}}{\eta_{e} \eta_{m} W_{G T}} .
$$

The $G T$ unit thermal efficiency $\eta_{G T}$ is equal to the net output divided by the caloric energy input to the thermal cycle, where $Q_{c v}$ is the fuel calorific.

$$
\eta_{G T}=\frac{P_{G T n e t}}{\dot{m}_{f} Q_{c v}}
$$

The fuel (natural gas) mass flow rate $\dot{m}_{f}$ is obtained from the energy balance applied to the combustion chamber. Subsequently the specific fuel consumption $s f c$ of $G T$ unit:

$$
s f c=\frac{\dot{m}_{f}}{P_{\text {GTnet }}} .
$$

This thermodynamic modelling is applied to evaluate $G T$ performance and exhaust gases conditions to the combined cycle. In modern and currently used gas turbines, the polytrophic efficiency for compressor and turbine $\eta_{p k}, \eta_{p T}$ respectively are about 0.9 and 0.91 [27], while the combustion chamber efficiency $\eta_{c c}$ is close to 98-100\% [29].The mechanical and electrical efficiency $\eta_{m}, \eta_{e}$ respectively are in the range of 97-99\%.Typical values of pressure drop in combustion chamber and HRSG are in between $2 \%-6 \%$ and for filters 0.005 to 0.015 bar [30]. GT model is validated for the design ambient temperature, as reported by Table 6 with good agreements for produced power; exhaust gases mass flow rates, temperatures and thermal efficiency.

GT validation results

Table 6

\begin{tabular}{|c|c|c|c|}
\hline Parameters & SGT-800 & Predicted & Error, \% \\
\hline $\begin{array}{c}\text { Compressor air } \\
\text { mass flow, kg/s }\end{array}$ & 129 & 124.2 & 3.7 \\
\hline $\begin{array}{c}\text { Exhaust gases mass } \\
\text { flow, kg/s }\end{array}$ & 131.5 & 126.8 & 3.5 \\
\hline $\begin{array}{c}\text { Exhaust gases tem- } \\
\text { perature, }{ }^{\circ} \mathrm{C}\end{array}$ & 544 & 542 & 0.3 \\
\hline $\begin{array}{c}\text { Gas turbine effi- } \\
\text { ciency, \% }\end{array}$ & 37.5 & 37.86 & 0.9 \\
\hline
\end{tabular}

\subsection{Steam generation}

In the design mode one can determine the gassteam temperature profiles, the duty of each component and the mass flow rate of steam generation. Design condi- tion is typically that of unfired mode of HRSG operation. This is done by simply selecting the pinch and the approach points at each evaporator level. In the low gas temperature heat recovery systems, the steam pressure and the pinch point play a crucial role in determining the gassteam temperature profiles, and the exit gas temperature from the economizer cannot be arbitrarily assumed [31]. A temperature profile analysis is performed to evaluate the steam generation. The exhaust gases parameters are exported to CC thermal cycle with the principle input parameters of HRSG are the gas temperature outlet $T_{g 4}$ and the gas mass flow $\dot{m}_{g}$. When the solar radiation is changing during the day, the exhaust gas flow rate temperature conditions or any of steam parameters also change, and thus the new properties are evaluated at each section from an iterative procedure.

By using the basic data given in Table 7 and the definitions of pinch point $\Delta T_{p p}=T_{g 5^{\prime}}-T_{s a t}$ and approach point $\Delta T_{a p p}=T_{s a t}-T_{w 7}$ the temperature profiles are shown by Fig. 2

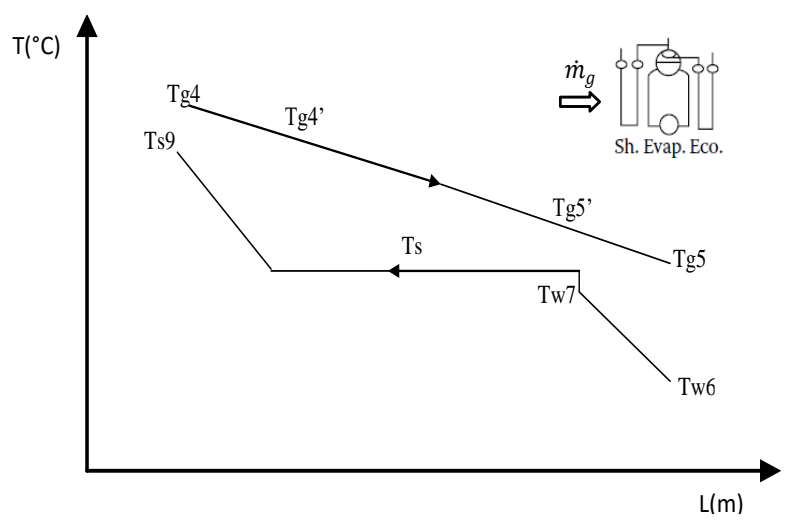

Fig. 2 Pinch point and approach point diagram

Table 7

Pinch and approach points [31]

\begin{tabular}{|c|c|c|c|}
\hline $\begin{array}{c}\text { Evaporator } \\
\text { Type }\end{array}$ & $\begin{array}{c}\text { Plain } \\
\text { Tubes }\end{array}$ & $\begin{array}{c}\text { Finned } \\
\text { Tubes }\end{array}$ & For both \\
\hline $\begin{array}{c}\text { gas inlet temp, } \\
{ }^{\circ} \mathrm{C}\end{array}$ & $\begin{array}{c}\text { pinch } \\
\text { point, }{ }^{\circ} \mathrm{C}\end{array}$ & $\begin{array}{c}\text { pinch point, } \\
{ }^{\circ} \mathrm{C}\end{array}$ & $\begin{array}{c}\text { approach } \\
\text { point, }{ }^{\circ} \mathrm{C}\end{array}$ \\
\hline $650-900$ & $60-85$ & $20-35$ & $20-40$ \\
\hline $375-650$ & $40-60$ & $5-20$ & $5-20$ \\
\hline
\end{tabular}

The determination of the steam generated (Table 8) during night or cloudy periods is carried out according to this following procedure.

Energy balance of superheater and evaporator:

$$
\dot{m}_{g} \bar{C}_{p g}\left(T_{g 4}-T_{g 5^{\prime}}\right)=\dot{m}_{s}\left(h_{s 9}-h_{s a t}\right),
$$

with $T_{g 5^{\prime}}=T_{\text {sat }}+\Delta T_{a p p}$,

$$
\dot{m}_{s}=\frac{\dot{m}_{g} \bar{C}_{p g}\left(T_{g 4}-T_{g 5^{\prime}}\right)}{\left(h_{s 9}-h_{s a t}\right)} .
$$

Energy balance of the economizer:

$$
\dot{m}_{g} \bar{C}_{p g}\left(T_{g 5^{\prime}}-T_{g 5}\right)=\dot{m}_{s}\left(h_{w 7}-h_{w 6}\right),
$$




$$
T_{g 5}=T_{g 5^{\prime}}-\frac{\dot{m}_{s}\left(h_{w 7}-h_{w 6}\right)}{\dot{m}_{g} \bar{C}_{p g}}
$$

ISCC power plant consists of two HRSGs; therefore, the target amount of steam generated is double. The obtained performances are listed in Table 9.
Table 8

HRSG parameters

\begin{tabular}{|c|c|c|c|c|c|c|}
\hline $\begin{array}{c}\dot{m}_{g}, \\
\mathrm{~kg} / \mathrm{s}\end{array}$ & $\begin{array}{c}T_{g 4}, \\
{ }^{\circ} \mathrm{C}\end{array}$ & $\begin{array}{c}T_{w 6}, \\
{ }^{\circ} \mathrm{C}\end{array}$ & $\begin{array}{c}\Delta T_{p p}, \\
{ }^{\circ} \mathrm{C}\end{array}$ & $\begin{array}{c}\Delta T_{a p}, \\
{ }^{\circ} \mathrm{C}\end{array}$ & $\begin{array}{c}T_{s 9}, \\
{ }^{\circ} \mathrm{C}\end{array}$ & $\begin{array}{c}P_{F P}, \\
\text { bar }\end{array}$ \\
\hline 126 & 542 & 45 & 11 & 8 & 500 & 93 \\
\hline
\end{tabular}

Table 9

HRSG performance at design point

\begin{tabular}{|c|c|c|c|c|c|c|c|c|}
\hline Surface & Gas temp & Wat $/$ Stm & Duty, & Press, & Mass flow, & Pinch, & Approach, & UA, \\
\hline--- & in/out, ${ }^{\circ} \mathrm{C}$ & in/out, ${ }^{\circ} \mathrm{C}$ & MW & bar & $\mathrm{kg} / \mathrm{s}$ & ${ }^{\circ} \mathrm{C}$ & ${ }^{\circ} \mathrm{C}$ & $\mathrm{kW} /{ }^{\circ} \mathrm{C}$ \\
\hline Sh & $542 / 473$ & $305.7 / 500$ & 10.97 & 93 & 16 & --- & --- & 120.54 \\
\hline Evap & $473 / 316$ & $297.7 / 305.7$ & 25.33 & 93 & 16 & 11 & 8 & 370.17 \\
\hline Eco & $316 / 205$ & $45 / 297.7$ & 18 & 93 & 16 & --- & --- & 272.22 \\
\hline
\end{tabular}

It is required to predict the performance of heat exchangers network HRSG and HSSG during sunny days while the solar radiation varies. In these calculations, several initial values were guessed before arriving iteratively at the final heat balance and the duty added to the steam generation.

The design value of $(U A)_{d}$ is corrected by using appropriate factors for gas properties and heat balance of each section. First, the temperature correction factor $F_{g}$ which reflects gas properties for each surface is computed, and then the transferred heat using the expression:

$$
Q=(U A) F_{g} \Delta T L M
$$

The steam flow rate $\dot{m}_{s}$ is assumed at first, and then iterations are required to arrive at the final value. The reference value of $(U A)$ is obtained from reference value of $Q$ and logarithmic mean temperature difference $\triangle T M L$ and the correction factor $F$ for each surface of the heat exchangers network such as super heater, evaporator, and economizer:

$$
(U A)_{d}=\left(\frac{Q}{F_{g} \Delta T L M}\right)_{d}
$$

Then the updated value of $(U A)$ is obtained using correction factors for gas flow and steam flow. The steam mass flow correction is not required for evaporator and economizer [32].

$$
(U A)=(U A)_{d}\left(\frac{\dot{m}_{g}}{\dot{m}_{g d}}\right)^{0.65}\left(\frac{F_{g}}{F_{g d}}\right)\left(\frac{\dot{m}_{s}}{\dot{m}_{s d}}\right)^{0.65} .
$$

\subsection{Calculation of steam generation}

As first solar beam appears, the plant works as ISCC and the amount of steam generated in the heat exchangers network which is the double enhances the electricity production. To recover some heat amount from the solar filed a solar steam generator HSSG is used, made up of one heat exchanger: evaporator section. The steam mass flow generated during the day is evaluated according to the following procedure referring to Figs. 3 and 4.

The first value of steam mass flow is assumed. a) Super heater level: assume $T_{s 9}$, then calculate $Q_{a}=\dot{m}_{s}^{\prime}\left(h_{s 9}-h_{s a t}\right)$ and $T_{g 4^{\prime}}=T_{g 4}-\frac{Q_{a}}{\dot{m}_{g} C_{p g}}$ calculate $Q_{t}=(U A) F_{g} \Delta T L M$ and $\Delta T L M=\frac{\left(T_{g 4^{\prime}}-T_{s a t}\right)-\left(T_{g 4}-T_{s 9}\right)}{\ln \frac{\left(T_{g 4^{\prime}}-T_{s a t}\right)}{\left(T_{g 4}-T_{s 9}\right)}}$

estimate $(U A)=(U A)_{d}\left(\frac{\dot{m}_{g}}{\dot{m}_{g d}}\right)^{0.65}\left(\frac{F_{g}}{F_{g d}}\right)\left(\frac{\dot{m}_{s}}{\dot{m}_{s d}}\right)^{0.65}$ check: $\frac{\left(Q_{a}-Q_{t}\right)}{Q_{a}}<\varepsilon$ then put $Q_{t}=Q_{1}$ and pass to the second step which is the evaporator level. If the assumed duty does not match the exhaust gases to the steam at the superheater level, the case $\frac{\left(Q_{a}-Q_{t}\right)}{Q_{a}} \geq \varepsilon$, another value of $T_{s 9}$ is assumed and the super heater calculations are repeated.

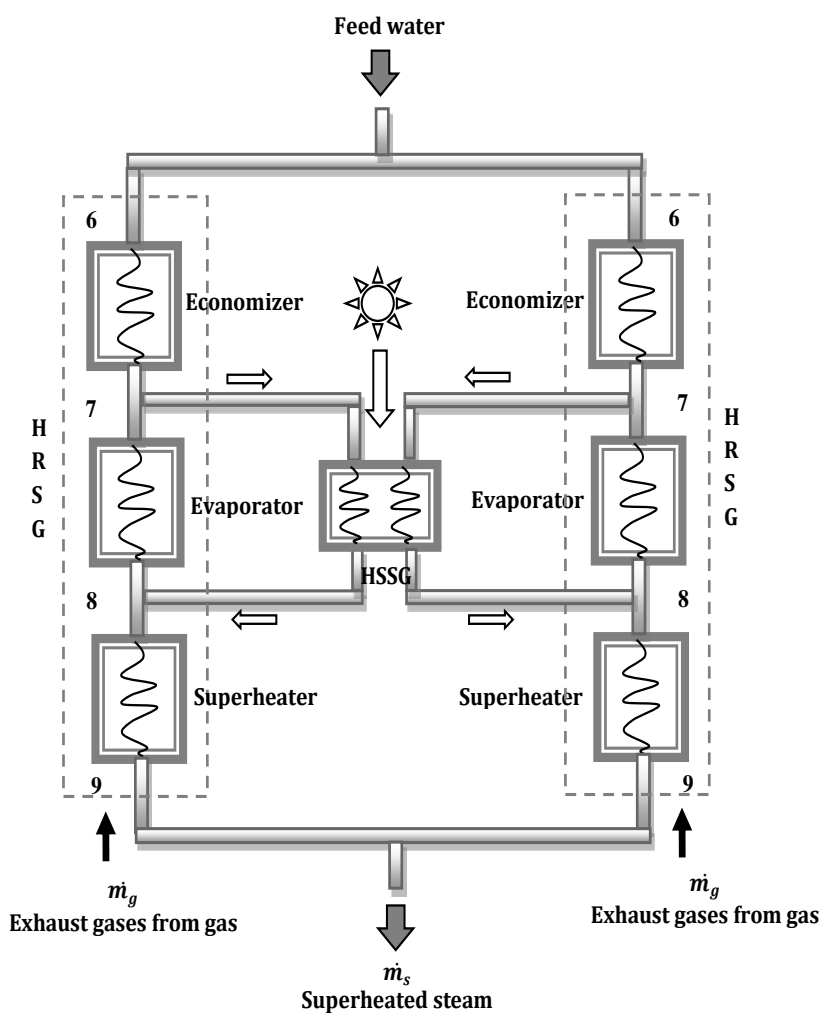

Fig. 3 ISCC heat exchangers network 


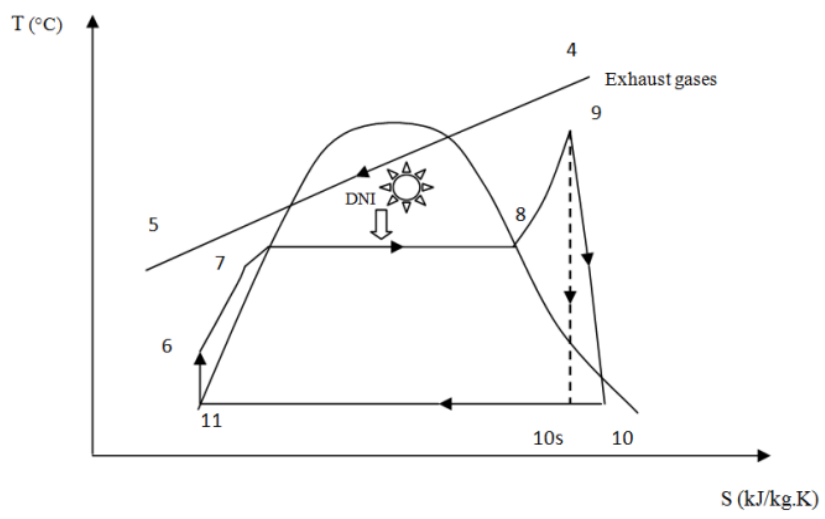

Fig. 4 Rankine-Hirn cycle

b) Evaporator level: $\ln \frac{\left(T_{g 4^{\prime}}-T_{s a t}\right)}{\left(T_{g 5^{\prime}}-T_{s a t}\right)}=\frac{U A}{\dot{m}_{g} C_{p g}}$ and $\ln \frac{\left(T_{g 4^{\prime}}-T_{\text {sat }}\right)}{\left(T_{g 5^{\prime}}-T_{\text {sat }}\right)}=K\left(\dot{m}_{g}\right)_{d}^{-0.4}$ with $K=f\left(\mathrm{~A} / \mathrm{C}_{p g}\right)$ $K=\left(\dot{m}_{g}\right)_{d}^{0.4} \ln \frac{\left(T_{g 4^{\prime}}-T_{\text {sat }}\right)}{\left(T_{g 5^{\prime}}-T_{\text {sat }}\right)}$. Then calculate $T_{g 5}{ }^{\prime}$ from: $\ln \frac{\left(T_{g 4^{\prime}}-T_{\text {sat }}\right)}{\left(T_{g 5^{\prime}}-T_{\text {sat }}\right)}=K\left(\dot{m}_{g}\right)_{d}^{-0.4}$ then $Q=\dot{m}_{g} C_{p g}\left(T_{g 4^{\prime}}-T_{g 5^{\prime}}\right)$ $Q_{2}=Q+\frac{Q_{S F}}{2}$ and $Q_{2}=\dot{m}_{s}{ }^{\prime}\left(h_{s a t}-h_{w 7}\right), \frac{Q_{S F}}{2}$ is solar energy carried by HTF and released to HSSG.

c) Economizer level: assume $T_{w 7}$ : $Q_{a}=\dot{m}_{s}{ }^{\prime}\left(h_{w 7}-h_{w 6}\right)$ and then $T_{g 5}=T_{g 5^{\prime}}-\frac{Q_{a}}{\dot{m}_{g} C_{p g}}$, $Q_{t}=(U A) F_{g} \Delta T L M$ with: $(U A)=(U A)_{d}\left(\frac{\dot{m}_{g}}{\dot{m}_{g d}}\right)^{0.65}\left(\frac{F_{g}}{F_{g d}}\right)$ and $\triangle T L M=\frac{\left(T_{g 5^{\prime}}-T_{w 7}\right)-\left(T_{g 5}-T_{w 6}\right)}{\ln \frac{\left(T_{g 5^{\prime}}-T_{w 7}\right)}{\left(T_{g 5}-T_{w 6}\right)}}$.

If the assumed duty does not match the exhaust gases to steam at economizer level, case $\frac{\left(Q_{a}-Q_{t}\right)}{Q_{a}} \geq \varepsilon$ assume another value of $T_{w 7}$ and repeat the economizer calculations by $Q_{3}=Q_{t}$ calculation of the steam mass $\dot{m}_{s}=\frac{\left(Q_{1}+Q_{2}+Q_{3}\right)}{\left(h_{s 9}-h_{w 6}\right)}$. Check: $\frac{\left(\dot{m}_{s}{ }^{\prime}-\dot{m}_{s}\right)}{\dot{m}_{s}{ }^{\prime}}<\varepsilon$. If the assumed steam mass flow value $\dot{m}_{s}$ doesn't match, the case $\frac{\left(\dot{m}_{s}{ }^{\prime}-\dot{m}_{s}\right)}{\dot{m}_{s}{ }^{\prime}} \geq \varepsilon$, the calculated steam mass flow rate is assigned as an assumed value and starts from the first step which is the superheater and repeat the whole calculation procedure.

It is assumed that the water feed pump outlet pressure is equal to $P_{F P}=93$ bars [24]. The input data are summarized in Table 10.

The mechanical work of steam is converted to electrical energy by a generator.

$$
W_{\text {STnet }}=\eta_{m} \eta_{e}\left(W_{S T}-W_{F P}\right)
$$

Table 10

Data to steam cycle

\begin{tabular}{|c|c|c|}
\hline Parameters & Symbols & Values \\
\hline $\begin{array}{c}\text { Ambient temperature and } \\
\text { pressure }\end{array}$ & $T_{a} \& P_{a}$ & $20^{\circ} \mathrm{C}$ and $1.013 \mathrm{bar}$ \\
\hline $\begin{array}{c}\text { HRSG steam outlet tem- } \\
\text { perature at design mode }\end{array}$ & $T_{w 9 d}$ & $500{ }^{\circ} \mathrm{C}$ \\
\hline $\begin{array}{c}\text { HRSG water inlet tem- } \\
\text { perature }\end{array}$ & $T_{w 6}$ & $45^{\circ} \mathrm{C}$ \\
\hline $\begin{array}{c}\text { water feed pump outlet } \\
\text { pressure }\end{array}$ & $P_{F P}$ & $93 \mathrm{bar}$ \\
\hline $\begin{array}{c}\text { Steam turbine mechani- } \\
\text { cal efficiency }\end{array}$ & $\eta_{m}$ & $98 \%$ \\
\hline $\begin{array}{c}\text { Steam turbine electrical } \\
\text { generator efficiency }\end{array}$ & $\eta_{e}$ & $98 \%$ \\
\hline
\end{tabular}

The plant net output is summed from $G T$ and $S T$ outputs.

$$
P_{\text {ISCC }}=2 P_{\text {GTnet }}+P_{\text {STnet }} \text {. }
$$

The power plant efficiency is calculated as the net energy produced divided by the total thermal energy provided from fuel:

$$
\eta_{I S C C}=\frac{P_{I S C C}}{\dot{m}_{f} Q_{c v}}
$$

The net solar electricity is the difference of the plant output between sunny and night periods. Therefore, solar electric ratio is given as follow:

$$
\text { Solareletricratio }=\frac{P_{I S C C}-P_{C C}}{P_{I S C C}},
$$

with: $P_{c c}$ is the plant output during night while it's operating as a $\mathrm{CC}$.

\section{Results and discussion}

From the sunrise to the sunset the power plant operates as ISCC while at night as $\mathrm{CC}$. The on-site average day temperature during $21^{\mathrm{st}}$ of March is equal to $20^{\circ} \mathrm{C}$ [26] which corresponds to the design conditions and selected as the reference day in the present numerical study where obtained results shown in figures below. The solar field subprogram calculates the supplied solar energy to HSSG which the Fig. 5 illustrates the variation of the DNI during the day and shows that at midday its maximum reaches $770 \mathrm{~W} / \mathrm{m}^{2}$. Fig. 6 shows the solar thermal output during the day which increases with the solar radiation from sunrise until sunset.

As shown by Fig. 7 the additional steam mass flow generated by HSSG fluctuates as a function of solar radiation and may reach a value of $65 \mathrm{~kg} / \mathrm{s}$ when the DNI reaches its maximum. As a result, the total steam turbine output (Fig. 8) is equal to $62 \mathrm{MW}$ and meaning that an increase in electricity generation about $27 \mathrm{MW}$ compared to that at night equal to $35 \mathrm{MW}$. 


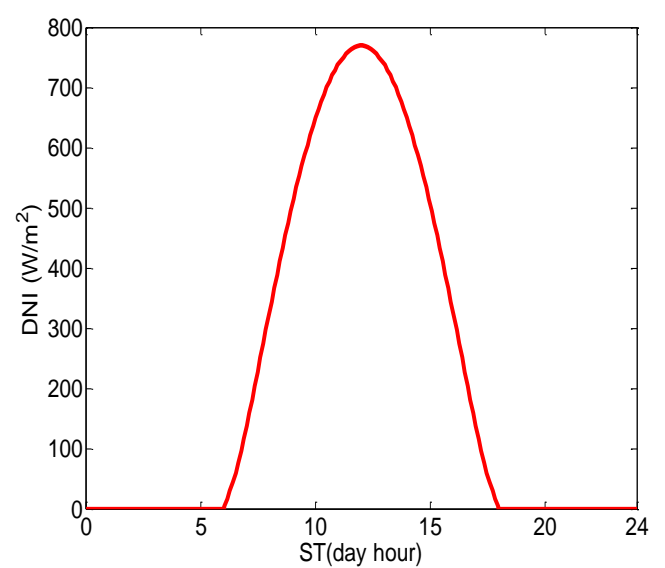

Fig. 5 The DNI

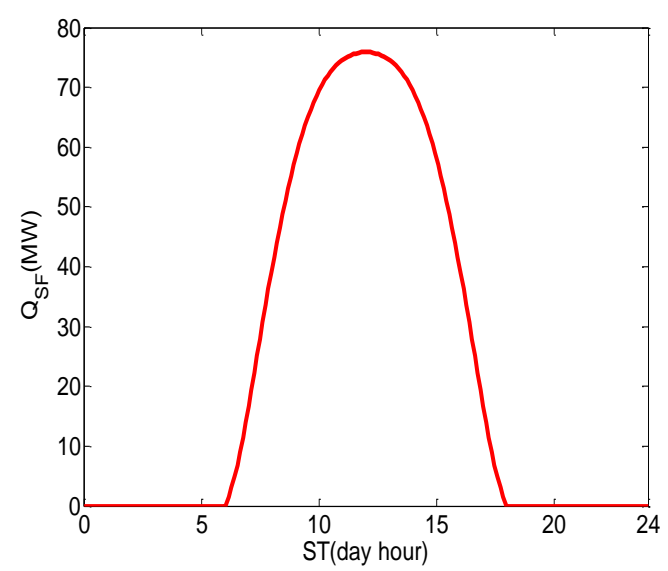

Fig. 6 Solar Field output

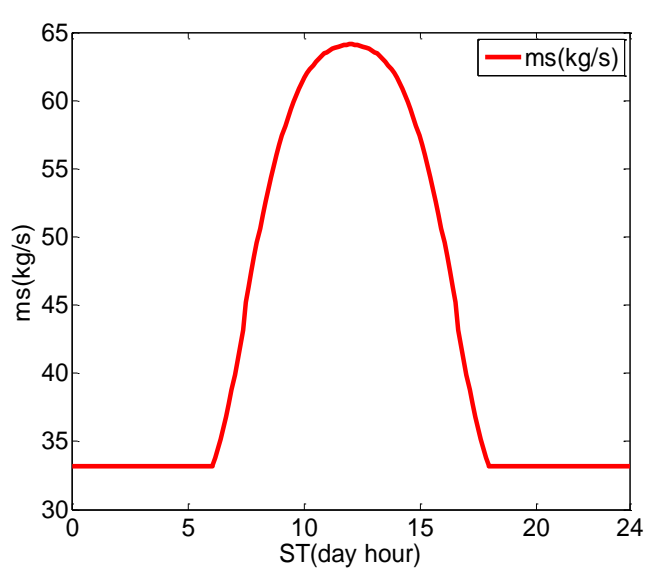

Fig. 7 Steam generated

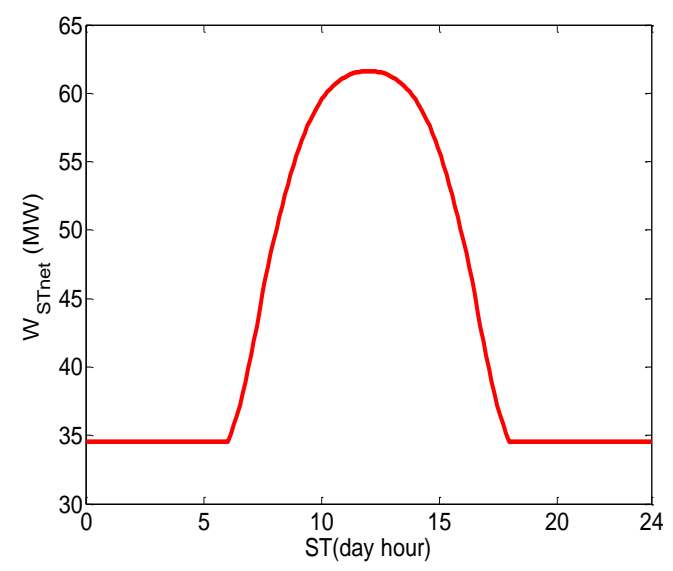

Fig. 8 Net steam turbine output
Fig. 9 gives an idea about the power plant output during the $21^{\text {st }}$ of March (design point) under Hassi R'mel climatic conditions. During the nights or cloudy periods ISCC operates as CC and produces about $129 \mathrm{MW}$ and its thermal efficiency reaches 52\%, according to Fig. 10. During the day, the net electricity production is increased to about $156 \mathrm{MW}$ where the highest efficiency of $63 \%$ is at midday. The estimated solar electricity ratio based on the difference in electrical output of ISCC mode and CC mode varies from sunrise to sunset according to the solar radiation fluctuations and its maximum reaches $17 \%$ at midday, as revealed by Fig. 11 .

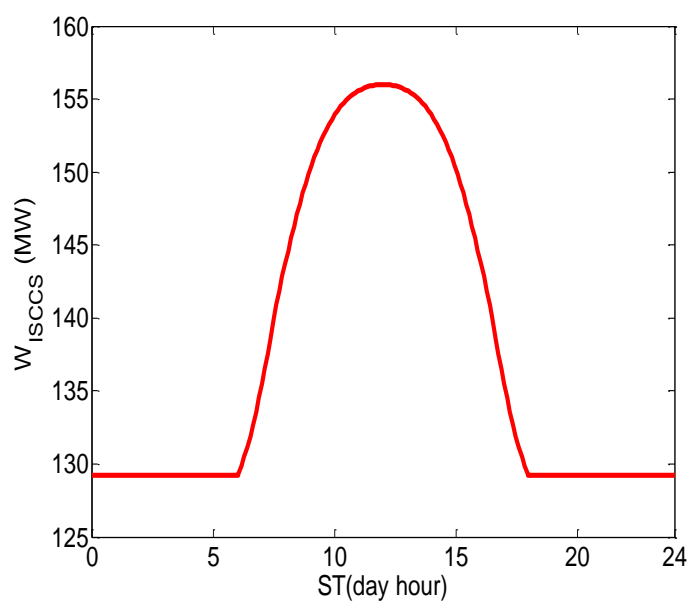

Fig. 9 ISCC output

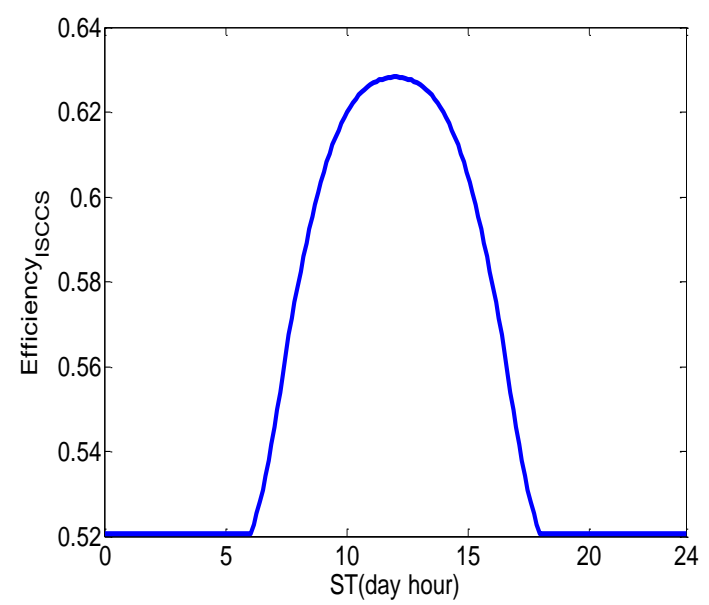

Fig. 10 ISCC efficiency

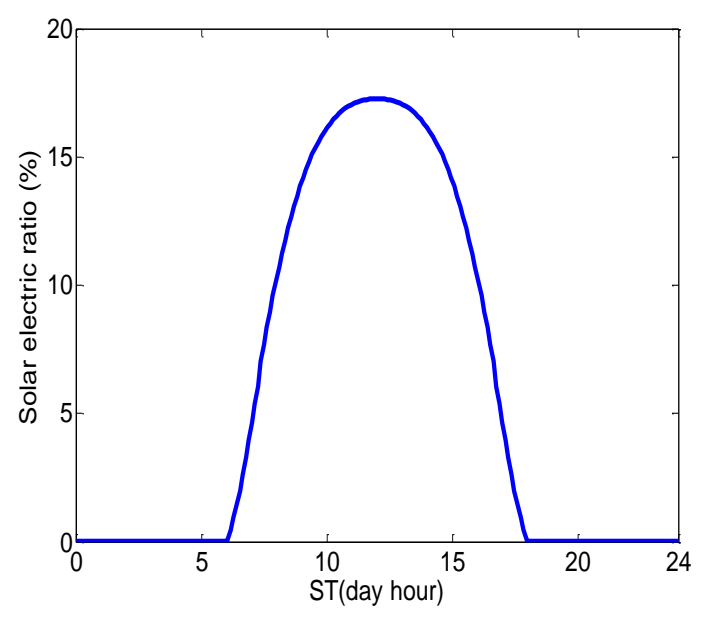

Fig. 11 Solar electric ratio 


\section{Economic assessment}

The economic assessment of $G T$ alone, $C C$ alone and ISCC power plant considers $L C O E$ to carry out comparison between these cases. The economic lifetime of ISCC are expected to reach 30 years [15], while the GT life expectancy is about 15 years, after which the replacement cost has to be considered for both ISCC and CC [14], [17]. The conventional $C C$ is taken as the reference power plant for the sake of comparison. The economic assumptions and data for this economic analysis are presented in Table 11.

The investor has to calculate $L C O E$ of power plant before starting the investment which is given in the units of currency (US dollar) per kilowatt-hour $(\$ / \mathrm{kWh})$, and can be calculated according to reference [13], [14] and [17].

$$
\begin{aligned}
& L C O E=\frac{(C R F C+O \& M+P V F)}{P_{e l_{-} a n}}, \\
& C R F=\frac{R}{\left(1-(1+R)^{-N}\right)},
\end{aligned}
$$

where: $C$ is the capital cost; $C R F$ is the cost recovery factor; $O \& M$ is the operation and maintenance; $P V F$ is the annual fuel cost; $P_{\text {el_an }}$ is the annual electrical energy production; $R$ is the discount rate; $N$ is the expected life time of power plant (Year).

$$
O \& M=k_{s o l} C_{s o l}+k_{s} C_{s}+k_{g} C_{g}
$$

\begin{tabular}{|c|c|}
\hline Assumptions and data & Value \\
\hline Life expectancy of solar field (year) & 30 \\
\hline Life expectancy of steam unit (year) & 30 \\
\hline Life expectancy of gas unit (year) & 15 \\
\hline Annual discount rate $R$ (year) & 10 \\
\hline Capacity factor & 0.8 \\
\hline \multicolumn{2}{|l|}{ Direct costs } \\
\hline Specific cost of solar field $C_{\text {sol }}(\$ / \mathrm{kW})$ & 1400 \\
\hline Specific cost of steam unit $C_{s}(\$ / \mathrm{kW})$ & 635 \\
\hline Specific cost of gas unit $C_{g}(\$ / \mathrm{kW})$ & 235 \\
\hline Contingency (\% of direct costs) & 10 \\
\hline $\begin{array}{c}\text { Indirect costs } \\
\text { Engineering, procurement and construction (\% of } \\
\text { direct costs) }\end{array}$ & 13 \\
\hline O\&M cost factor of solar field $K_{\text {sol }}(\%)$ & 1.5 \\
\hline O\&M cost factor of steam unit $K_{s}(\%)$ & 2 \\
\hline O\&M cost factor of gas unit $K_{g}(\%)$ & 5 \\
\hline Natural gas calorific value $Q_{c v}(\mathrm{~kJ} / \mathrm{kg})$ & 45806 \\
\hline Fuel price $\left(\$ / \mathrm{m}^{3}\right)$ & 0.045 \\
\hline Emissions $(\$ / \mathrm{kWh})$ & 0.0073 \\
\hline
\end{tabular}

Table 11

Assumptions and Data [13], [14], [33]

The total investment cost for ISCC is the sum of $G T, S T$, and solar unite cost. The operation and maintenance costs $(O \& M)$ include labour, spare parts; consumables and normal maintenance equipment are estimated [14] as given by Table 11 .
Table 12 compares between the three power plants in terms of $L C O E$, fuel saving and emission, considering the $C C$ as the reference power plant

Table 12

Estimated $L C O E$

\begin{tabular}{|c|c|c|c|}
\hline Parameter & $G T$ & $C C$ & $I S C C$ \\
\hline DNI per year, $\mathrm{kWh} / \mathrm{m}^{2} \mathrm{yr}$ & --- & --- & 1999.38 \\
\hline $\begin{array}{c}\text { Annual electricity produc- } \\
\text { tion, MWh }\end{array}$ & $\begin{array}{c}65875 \\
2\end{array}$ & 909228 & 972896.8 \\
\hline$L C O E^{a}, \$ / \mathrm{kWh}$ & 0.0216 & 0.0174 & 0.0222 \\
\hline$L C O E^{b}, \$ / \mathrm{kWh}$ & 0.0289 & 0.0227 & 0.0272 \\
\hline $\begin{array}{c}\text { Fuel saving in 30 years, } \\
\text { Million \$ }\end{array}$ & --- & --- & 18.45 \\
\hline $\begin{array}{c}\text { Avoided } \mathrm{CO}_{2} \text { emission in } \\
30 \text { years, Million Ton }\end{array}$ & --- & --- & 0.89 \\
\hline
\end{tabular}

${ }^{\mathrm{a}}$ Without considering environmental cost

${ }^{\mathrm{b}}$ With considering environmental cost

Figs. 12 and 13 show the calculated LCOE divided into three parts: investment cost, $O \& M$ cost and fuel cost. The $L C O E$ is greatly affected by the specific cost of power plant, especially for the solar parts, since their costs are very high compared to the fossil parts. According to Fig. 12 when the environmental cost is not taken into consideration, $C C$ power plant has the lowest $L C O E$ followed by $G T$. In the case of ISCC, LCOE is $3 \%$ higher than that of $G T$ and $28 \%$ higher than that of $C C$. If one considers the environmental effects as shown by Fig. 13, LCOE of ISCC becomes $0.0272 \$ / \mathrm{kWh}$ which is about $6 \%$ lower than for $G T$ and $20 \%$ higher than CC, however $L C O E$ of $C C$ is still the lowest.

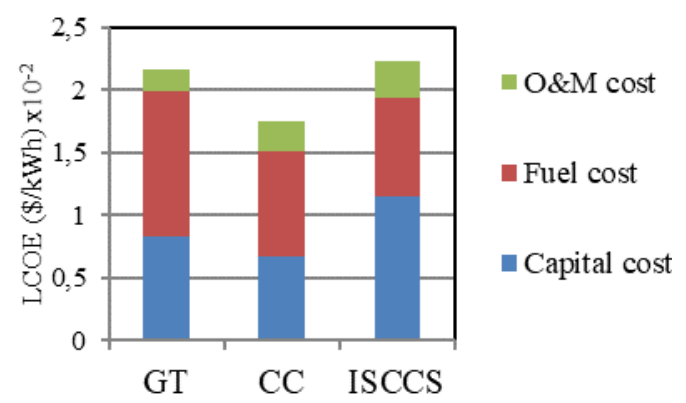

Fig. 12 LCOE of different power plants without environmental cost

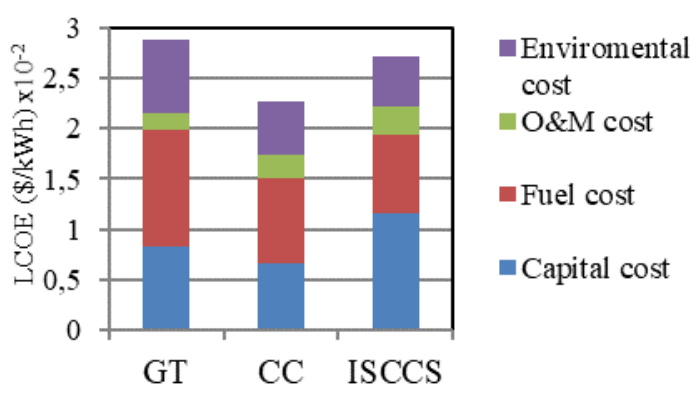

Fig. $13 L C O E$ of different power plants by considering environmental cost

Figs. 14 and 15 show the specific fuel consumption $(\mathrm{kg} / \mathrm{MWh})$ and $\mathrm{CO}_{2}$ emission $(\mathrm{kg} / \mathrm{MWh})$ respectively. ISCC has the lowest specific fuel consumption about $7 \%$ which is lower than $C C$ and $32 \%$ lower than $G T$. As a consequence, ISCC saves about 18.45 million $\$$ of fuel consumption through 30 years of its operation. Fig. 15 permits 
concluding that $\mathrm{CO}_{2}$ emission is proportional to the fuel consumed by the power plant which is extremely high in $G T$ but less in $C C$ power plant. Due to availability of the solar energy during the day, ISCC produced the lowest $\mathrm{CO}_{2}$ emission, thus avoiding 0.89 million ton of $\mathrm{CO}_{2}$ emission over 30 years of its operational period.

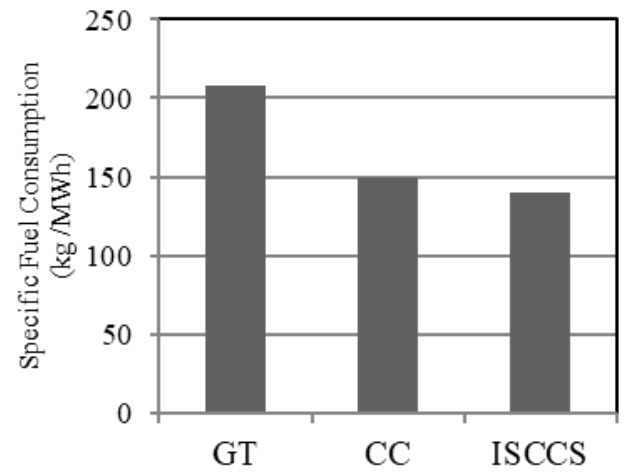

Fig. 14 Natural gas specific consumption of different power plants

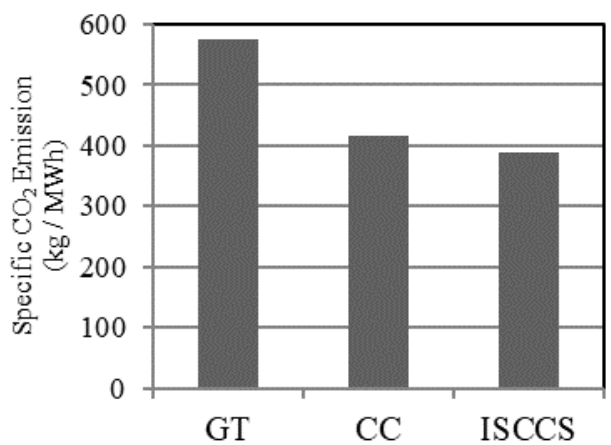

Fig. 15 Specific $\mathrm{CO}_{2}$ emission of different power plants

\section{Conclusion}

The thermo-economic investigations of the first integrated solar combined cycle system in Algeria has been carried out in the present work. Therefore, thermodynamic study of such ISCC power plant configuration has shown that during daytime the solar energy can be converted for a net solar electricity ratio about $17 \%$ and a thermal efficiency more than $63 \%$ which are significantly higher than for $C C$ with the global output reaches the value of 156 MW. The Levelized Cost of Energy ( $L C O E$ ) generated by the $I S C C$ is of $2.22 \$ \notin / \mathrm{kWh}$, about $28 \%$ higher than the $C C$ without considering environment cost effect. In case where the environmental cost is considered, the $L C O E$ of ISCC decreases in terms of percentage, which is about $20 \%$ higher than $C C$. The annual solar contribution of ISCC results in fuel consumption about $140 \mathrm{~kg} / \mathrm{MWh}$ which is about $7 \%$ lower than $C C$, thus saving about 18.45 million $\$$ of fuel through 30 years of operation. Moreover, $\mathrm{CO}_{2}$ emission is lowered by reducing 0.89 million ton rejected over 30 years. The integration of fossil fuel - natural gas with solar energy for the replacement of the latent heat by using $H S S G$ in parallel with $H R S G$ is a very promising option to make the transition from simple the $G T$ and $C C$ to the ISCC power plants. The results obtained from this study confirm well the feasibility and benefits by integrating the solar technology, which is being considered as a part of the Algerian program aimed to produce $22000 \mathrm{MWe}$ of renewable to the horizon of 2030.

\section{Acknowledgements}

The support from Directorate-General for Scientific Research and Technological Development (DGSRDT) of Algerian government in the form of research grand to Prof. A. Smaili is gratefully acknowledged.

\section{References}

1. Goswami, D. Y.; Kreith, F. 2007. Energy conversion, Taylor \& Francis Group, USA.

2. Zachary, J. 2013. Integrated solar combined cycle (ISCC) systems, Bechtel Corp, USA.

3. Dersch, J.; Geyer, M.; Geyer, M.; Herrmann, U.; Jones, SA.; Kelly, B.; Kistner, R.; Ortmanns, W.; Pitz-Paal, R.; Price, H. 2004. Trough integration into power plants-a study on the performance and economy of integrated solar combined cycle systems, Energy 29(5-6): 947-959. https://doi.org/10.1016/S0360-5442(03)00199-3.

4. Montes, M. J.; Rovira; A.; Muñoz, M.; MartínezVal, J. M. 2011. Performance analysis of an integrated solar combined cycle using direct steam generation in parabolic trough collectors, Applied Energy 88(9): 3228-3238.

https://doi.org/10.1016/j.apenergy.2011.03.038.

5. Antonanzas, J.; Jimenez, E.; Blanco, J.; Antonanzas-Torres, F. 2014. Potential solar thermal integration in Spanish combined cycle gas turbines, Renewable and Sustainable Energy Reviews 37: 3736-46. https://doi.org/10.1016/j.rser.2014.05.006.

6. Zhu, G.; Neises, T.; Turchi, C.; Bedilion, R. 2015. Thermodynamic evaluation of solar integration into a natural gas combined cycle power plant, Renewable Energy 74: 815-824. https://doi.org/10.1016/j.renene.2014.08.073.

7. Bataineh, K. 2015. Analysis and design consideration of solar steam generation plant using parabolic trough collector, Mechanika 21(5): 384-392.

http://dx.doi.org/10.5755/j01.mech.21.5.9834.

8. Benabderrahmane, A, Benazza, A, Laouedj, S, Solano, J. P. 2017.Numerical analysis of compound heat transfer enhancement by single and two-phase models in parabolic through solar receiver, Mechanika 23(1): 55-61.

http://dx.doi.org/10.5755/j01.mech.23.1.14053.

9. Franchini, G.; Perdichizzi, A.; Ravelli, S.; Barigozzi, G. 2013. A comparative study between parabolic trough and solar tower technologies in Solar Rankine Cycle and Integrated Solar Combined Cycle plants, Solar Energy 98:302-314. http://dx.doi.org/10.1016/j.solener.2013.09.033.

10. Abdel-Dayem, A. M.; Metwally, M. N.; Alghamdi, A. S.; Marzouk, E. M.2014. Numerical simulation and experimental validation of integrated solar combined power plant, Energy Procedia 50:290-305. https://doi.org/10.1016/j.egypro.2014.06.036.

11. Aldali, Y.; Morad, K. 2016. Numerical simulation of the integrated solar/North Benghazi combined power plant, Applied Thermal Engineering 108: 785-792. http://dx.doi.org/10.1016/j.applthermaleng.2016.07.178

12. Price, H.; Kearney, D.2003. Reducing the cost of energy from parabolic trough solar power plants, National 
Renewable Energy Laboratory, NREL/CP-550-33208, USA.

13. Horn, M.; Fuhring, H.; Rheinlander, J. 2004. Economic analysis of integrated solar combined cycle power plants. Energy 29: 935-945. http://dx.doi:10.1016/S0360-5442(03)00198-1.

14. Hosseini, R.; Soltani, M.; Valizadeh, G. 2005. Technical and economic assessment of the integrated solar combined cycle power plants in Iran, Renewable Energy 30(10): 1541-1555. https://doi.org/10.1016/j.renene.2004.11.005.

15. Mokheimer, E. M. A.; Dabwan, Y. N.; Habib, M. A. 2015. Optimal integration of solar energy with fossil fuel gas turbine cogeneration plants using three different CSP technologies in Saudi Arabia, Journal of Applied Energy185(2,1): 1268-1280. https://doi.org/10.1016/j.apenergy.2015.12.029

16. Duan, L.; Qu, W.; Jia, S.; Feng, T. 2017. Study on the integration characteristics of a novel integrated solar combined cycle system, Energy 130: 351-364, http://dx.doi.org/10.1016/j.energy.2017.04.118.

17. Li, Y.; Xiong, Y. 2018. Thermo-economic analysis of a novel cascade integrated solar combined cycle system, Energy 145: 116-127. https://doi.org/10.1016/j.energy.2017.12.128.

18. Behar, O.; Khellaf, A.; Mohamedi, K.; Belhamel, M. 2011.Instantaneous performance of the first Integrated Solar Combined Cycle System in Algeria, Energy Procedia 6: 185-193. https://doi.org/10.1016/j.egypro.2011.05.022.

19. Derbal-Mokrane, H.; Bouaichaoui, S.; Gharbi, N. E.; Belhamel, M.; Benzaoui, A. 2012. Modeling and numerical simulation of an Integrated Solar Combined Cycle. Procedia Engineering 33: 199-208. http://dx.doi:10.1016/j.proeng.2012.01.1194.

20. Achour, L.; Bouharkat, M.; Mohamedi, K.; Behar, O. 2018. Performance assessment of an integrated solar combined cycle in the southern of Algeria, Energy Reports 4: 207-217. https://doi.org/10.1016/j.egypro.2011.05.022.

21. Price, H.; Lüpfert, E.; Kearney, D.; Zarza, E.; Cohen, G.; Gee, R.; Mahoney, R.2002. Advances in parabolic trough solar power plants, Journal of Solar Energy Engineering 124: 109-125. http://dx.doi:10.1115/1.1467922.

22. Zarza Romero-Alvarez, M. 2007. Concentrating solar thermal Power, Plataforma Solar de Almeria-CIEMAT, Chap 21, Taylor \& Francis Group.

23. Duffie, A. J.; Beckman, A. W. 1991. Solar engineering of thermal processes, 2nd edition, Wiley, New York.24. ISCC Hassi-R'mel power plant, 2014, Operating manual.

25. Cohen, G. E.; Kearny, D. W, Gregory, J. K. 1999. Final report on the operation and maintenance improvement program for concentrating solar power plants, SAND 99-1290 p.

26. National meteorological Office (ONM). 2014, Report, Algeria.
27. Horlock, J. H. 2003. Advanced gas turbine cycles, Elsevier Science Ltd, UK.

28. Wilcock, R. C.; Young, J. B.; Horlock, J. H. 2005. The effect of turbine blade cooling on the cycle efficiency of gas turbine power cycles, Journal of Engineering for Gas turbines and Power 127(1): 109-120.

29. Razak, A. M. Y. 2007. Industrial gas turbines 'Performance and operability', Taylor \& Francis Group, USA.

30. Kim, T. S.; Ro, S. T. 1995. Comparative evaluation of the effect of turbine configuration on the performance of heavy-duty gas turbines, ASME95-GT-334: V004T10A019. http://dx.doi:10.1115/95-GT-334.

31. Ganapathy, V. 2003. Industrial boilers and heat recovery steam generators, Marcel Dekker, USA

32. Ganapathy, V. 2015. Steam generators and waste heat boilers for process and plant engineers, Taylor \& Francis Group, USA.

33. Zeroual, B.; Moummi, A.; Smaili, A. 2015 Technoeconomic assessment of an integrated solar combined cycle power plant in semi-arid region in Algeria, Policies \& Management, Proceeding of 14th International Conference on Sustainable Energy Technologies, Nottingham. UK. P 515-25.

M. Amani, A. Smaili, A. Ghenaiet

\section{THERMO-ECONOMIC ASSESSMENT OF THE FIRST INTEGRATED SOLAR COMBINED CYCLE SYSTEM OF HASSI R'MEL}

$\mathrm{S}$ u m m a r y

The aim of this study is the thermo-economic assessment of an integrated solar combined cycle ISCC system, in terms of thermal efficiency and levelized cost of energy ( $L C O E)$. During the day, the power plant operates as an ISCC and operates as a conventional combined cycle (CC) during the night or cloudy days. The obtained results show that the solar electricity ratio may reach about $17 \%$ and the global thermal efficiency $63 \%$, leading to lower fuel consumption and carbon emission. On the other hand, the economic assessment depicts that $L C O E$ may reach $0.0222 \$ / \mathrm{kWh}$, which is about $28 \%$ higher than that of $(C C)$ power plants. Furthermore, by introducing the environmental effect $L C O E$ becomes equal to $0.0272 \$ / \mathrm{kWh}$ which is higher. Therefore, the solar contribution relatively to this installation will allow about 18.45 million $\$$ of fuel saving, avoiding the emission of 0.89 million ton of $\mathrm{CO}_{2}$ over lifetime operation.

Keywords: integrated solar combined cycle, parabolic trough collector, $L C O E$, thermal analysis.

Received August 26, 2019

Accepted June 02, 2020 